\title{
ORIENTATION TRAINING FOR EMPLOYEES TO REDUCE THE TURNOVER RATE IN AJAD INTERNATIONAL SCHOOL
}

\author{
Hessah Al-Dossary \\ Prince Mohammed Bin Fahad University, Al-Khobar, Saudi Arabia \\ Email: hessah.1985@hotmail.com
}

\begin{abstract}
This research explores the most prominent factor that leads to high employee turnover and leads to dissatisfaction with the working environment. I conducted the self-assessment in order to check whether the school meets the standard that it should be at or not. I conducted this by giving the employees a protocol that has some questions about the school. This questionnaire is adopted from Massachusetts Cultural Council. It is an ethnographical research which uses mixed methods design and associate qualitative, along with quantitative data analysis. I used three techniques namely observation, interview and document analysis. The aim of this study is to design a program to reduce the rate of employee turnover at Ajad School through orientation training. This will help to reduce job tardiness as it will facilitate increased job satisfaction, better understanding of employee's roles and thus, improve their job performance. Overall, results revealed a deficiency in proper training of new employees. Lack of orientation training meant that employees were unaware of their job descriptions, their duties and what was expected of them. As a result, the employees found it difficult to accomplish basic tasks, were dissatisfied with their work and the company and this greatly affected their performance. Lack of orientation training was, as such, the cause for the high employee turnover in the school.
\end{abstract}

Keywords: Employees Turnover, Orientation, Dissatisfaction

\section{Overview of the Ministry of Education, Higher education}

The Kingdom of Saudi Arabia places a lot of importance on education as it views knowledge as the foundation to a nation's renaissance. As a result, King Abdullah Bin Abdulaziz Al Saud started an initiative aimed at launching the scholarship program dubbed 'King Abdullah'. Its aim is to support both public and private universities through the provision of qualified citizens and an enhanced human resource. This would help the universities create better citizens and help them to compete at international levels in the global market (Ministry of Education, 2015).

\subsection{Mission}

"To prepare and qualify Saudi human resources in an effective manner so that they will be able to compete on an international level in the labor market and the different areas of scientific research, and thereby become an important source of supply of highly qualified individuals for Saudi universities as well as the government and private sectors" (Ministry of education, 2015).

\subsection{Vision}

"To prepare distinguished generations for a knowledge society built upon a knowledge-based economy" (Ministry of education, 2015).

\subsection{Overview of Ajaad International schools}

One of the leading schools in eastern province is Aajad International School. The school provides its service to students in certain grades which starts from nursery to grade VI. School's 
endeavor is to help every child realize academic, social and emotional success. Their pursuit of excellence goes a long way in building positive and qualitative connections between all the stakeholders. Aajad strongly believes that academic pursuits, sportsmanship, creative and aesthetic ideas go hand in hand with developing personal values and ability to make a difference in the society we live in. it believes in imparting best and qualitative education to the students through advanced educational system and innovative ideas.

The schools are run by teams comprising of the principals, his deputy and various heads of departments. They are in charge of ensuring that there is a positive change in the school through proper administration and training. The schools rely on school based management for the autonomy of each school with the belief that the stakeholders and the community play a big role in governing most of the daily activities and can assist in make good decisions within the organization. All members have a role to play in the schools and the managers have various responsibilities. This include selecting team members, assessing needs, assigning committees, making decisions, conducting research and developing staff to mention a few (Ajaad International Schools, 2015).

\section{Mission}

"The mission of the AJAAD SCHOOL is to provide a collaborative and caring community in which each student is known, understood, and valued so that students can learn to their fullest potential in a safe, inclusive environment with high expectations and clear standards for all” (Ajaad International Schools, 2015).

\subsection{Vision}

"The vision of the AJAAD SCHOOL is to inspire intellectual and ethical excellence so our students are prepared to participate with integrity in a global community" (Ajaad International Schools, 2015).

\section{Self-Assessment 3.2 School self-assessment}

I conducted the self-assessment in order to check whether the school meets the standard that it should be on or not. I conducted this by giving the employees in the school a protocol that has some questions about the school. In fact, self-assessment will enlighten me about the school and if there are gaps or none, and it will drive me to choose the model. From a researcher's viewpoint, I believe that these questions are important for them in order to develop certain understanding on how to increase performance.

Self-assessment refers to a systemic process where an individual or organization's management conducts a deliberate reflection on data related to the performance and performance objectives. It is a comprehensive data driven analysis where one conducts a self-reflection (New Zealand Qualification Authority, n.d). Self-assessment is aimed towards achieving clear and coherently articulated objectives to inform the decision making and the operational practices of an individual or organization. Self-assessment is a powerful tool for a school or a Tertiary Education Organization (TEO) in understanding and improving its educational performance (New Zealand Qualification Authority, n.d). Examples of self-assessment include a cover peer or self-assessment of a particular assignment, curriculum evaluation, evaluation of pupils' yearly performance in relation to skill and knowledge-based targets (Towler \& Broadfoot, 2006). A self-assessment review is needed when periodically for long term goals, and at period ends for 
short term goals. According to Noonan \& Duncan (2005), self-assessment can be done by use of rubrics with variables used to measure performance. To use self-assessment rubrics successfully, one should set clear goals and use effective feedback from others providing the opportunity for self-reflection and correction (Noonan \& Duncan, 2005).

This questionnaire is adopted from Massachusetts Cultural Council. It is designed to help assess the organization. It will help affirm strengths and identify weaknesses and areas that need attention. I presented the non-teaching staffs and the teachers with a sample of questionnaires whereby they were to answer fourteen questions in the questionnaire. I analyzed the results of the assessment that I conducted below. I asked them not to write their names and I explained clearly that the survey is confidential and it will be only used for my degree and the results will not be shared with anyone else. At the end of the day I collected the results and I used Excel to analyze the results as shown below in the table. The table shows the frequencies, percentages and average of the results.

These are the response choices for each statement:

1. I agree (this statement is certainly true for my organization).

2. I agree slightly (this statement is sometimes or partly true).

3. Uncertain (I don't know).

4. I disagree slightly (this statement is usually not true).

5. I disagree (this statement is certainly not true for my organization).

Theme -1- (Mission and Vision)

\section{First research question: Do the employees aware of the mission and vision of the} school?

1. Organization has a clear, concise mission statement that communicates its reason for existence.

$\begin{array}{cccccc}\begin{array}{c}\text { strongly } \\ \text { agree }\end{array} & \text { agree } & \text { neutral } & \text { disagree } & \begin{array}{c}\text { strongly } \\ \text { disagree }\end{array} & \text { Total } \\ 7 \% & 20 \% & 13 \% & 53 \% & 7 \% & 100 \% \\ 1 & 3 & 2 & 8 & 1 & 15\end{array}$

The graph shows that more than $53 \%$ of the respondents disagreed that the organization has a clear and concise mission statement that communicates the reason for its existence. This means that the organization does not normally have a clear and concise mission statement.

2. Organization has a compelling vision statement that communicates what the organization aspires to accomplish. 


\section{Asia Pacific Journal of Contemporary Education and Communication Technology \\ ISBN (eBook): 9780994365682 | ISSN : 2205-6181 \\ Year: 2017 , Volume: 3, Issue: 2}

strongly

agree

$7 \%$

1 agree

$$
27 \%
$$

4 neutral

disagree

$7 \%$

1 strongly

disagree

$0 \%$

O
Total

$100 \%$

15

The graph shows that $60 \%$ of the respondents disagreed that the organization has a compelling vision statement. This means that the organization's vision statement is not compelling and does not communicate what the organizations aspires to accomplish.

\section{Result-1}

With regards to theme one (Mission and Vision), I found that the school has a vague mission and vision statement that does not clarify the direction and whatever the organization wants to accomplish. An unclear mission and vision statement makes it difficult to evaluate performance as it would not be easily discernible when the organization's aspirations have been achieved. The mission and vision statement of an organization are known to give the long term general direction of the organization and helps define the limits of its engagement in particular activities.

\section{Theme -2- (Human Resources)}

Second research question: To what extent are the Human Resource Management practices in recruitment and placement, training and development, performance appraisal, compensation and benefits and employee relations implemented by the school?

3. Well-defined policies are followed for employee recruitment, application and interview processes.

$\begin{array}{cccccc}\begin{array}{c}\text { strongly } \\ \text { agree }\end{array} & \text { agree } & \text { neutral } & \text { disagree } & \begin{array}{c}\text { strongly } \\ \text { disagree }\end{array} & \text { Total } \\ 7 \% & 33 \% & 0 \% & 47 \% & 13 \% & 100 \% \\ 1 & 5 & 0 & 7 & 2 & 15\end{array}$




\section{Asia Pacific Journal of Contemporary Education and Communication Technology \\ ISBN (eBook): 9780994365682 | ISSN : 2205-6181 \\ Year: 2017 , Volume: 3, Issue: 2}

A P I A R

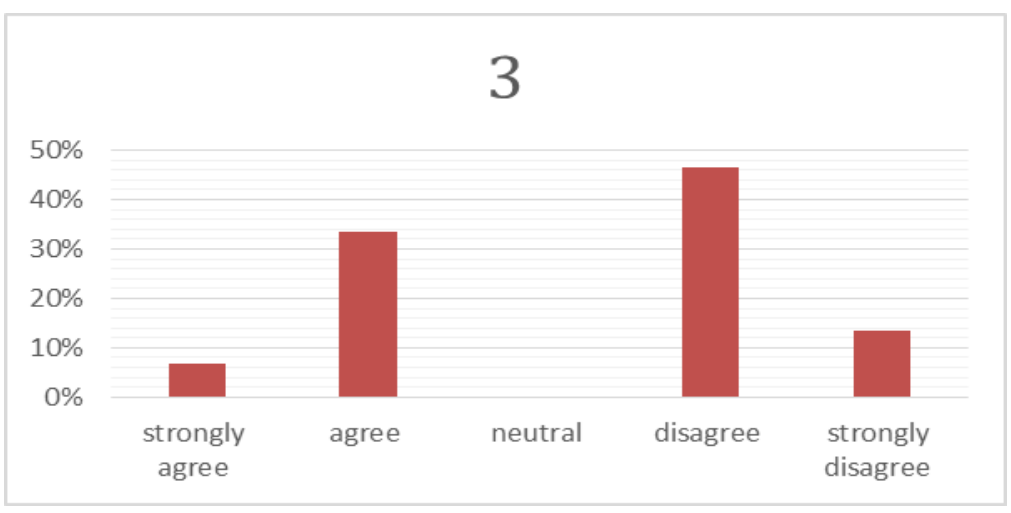

More than half or the total respondents population either disagree or strongly disagree that the organization follows well-defined recruitment, application, and interview policies. This means that most of the employees of the organization do not meet the employability threshold of the organization therefore compromising the quality of their services.

4. Recruitment process respects and encourages applicants that represent the diversity of the community.

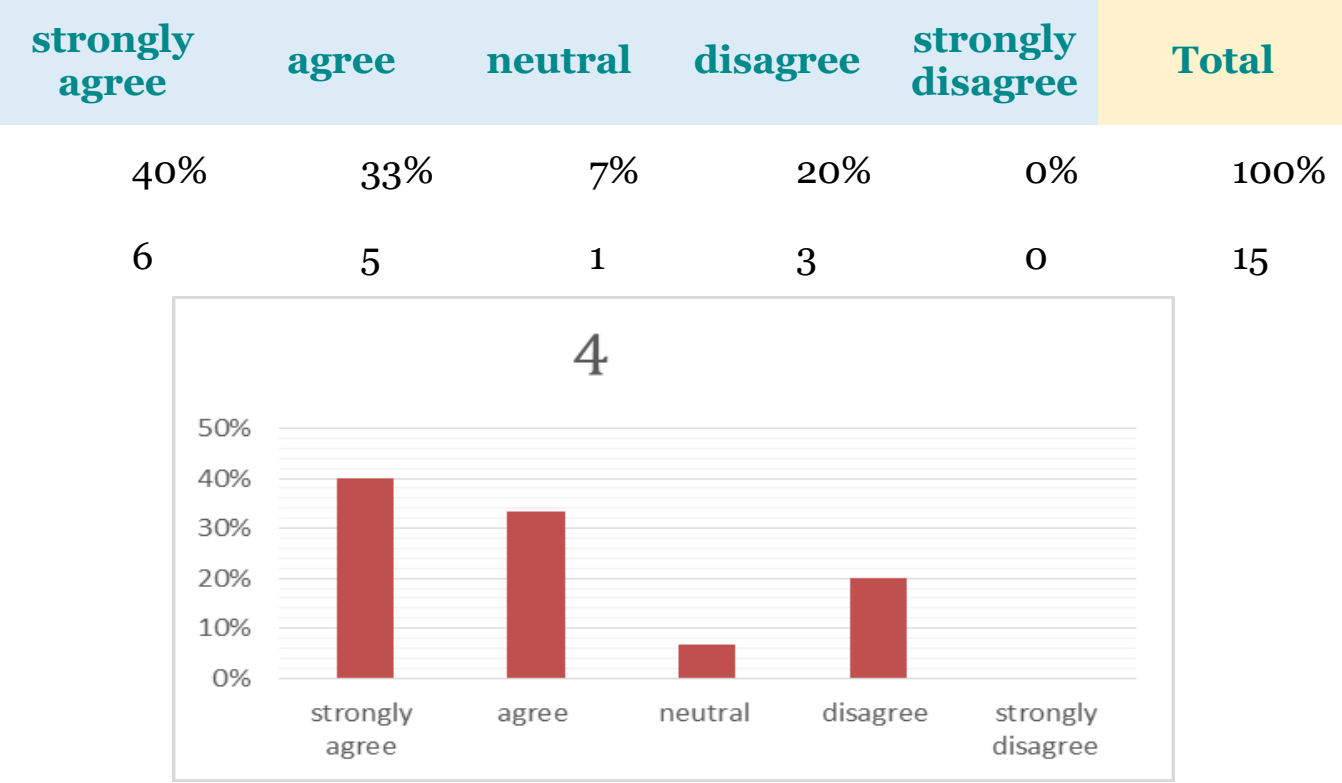

Most of the respondents, more than 50\%, either agrees or strongly agree that applicants represent diversity of the community. This means that employees of the school diversely represent the community. 
Asia Pacific Journal of Contemporary Education and Communication Technology

ISBN (eBook): 9780994365682 | ISSN : 2205-6181

Year: 2017, Volume: 3, Issue: 2

A P I A R

5. Someone on staff is responsible for human resource management.

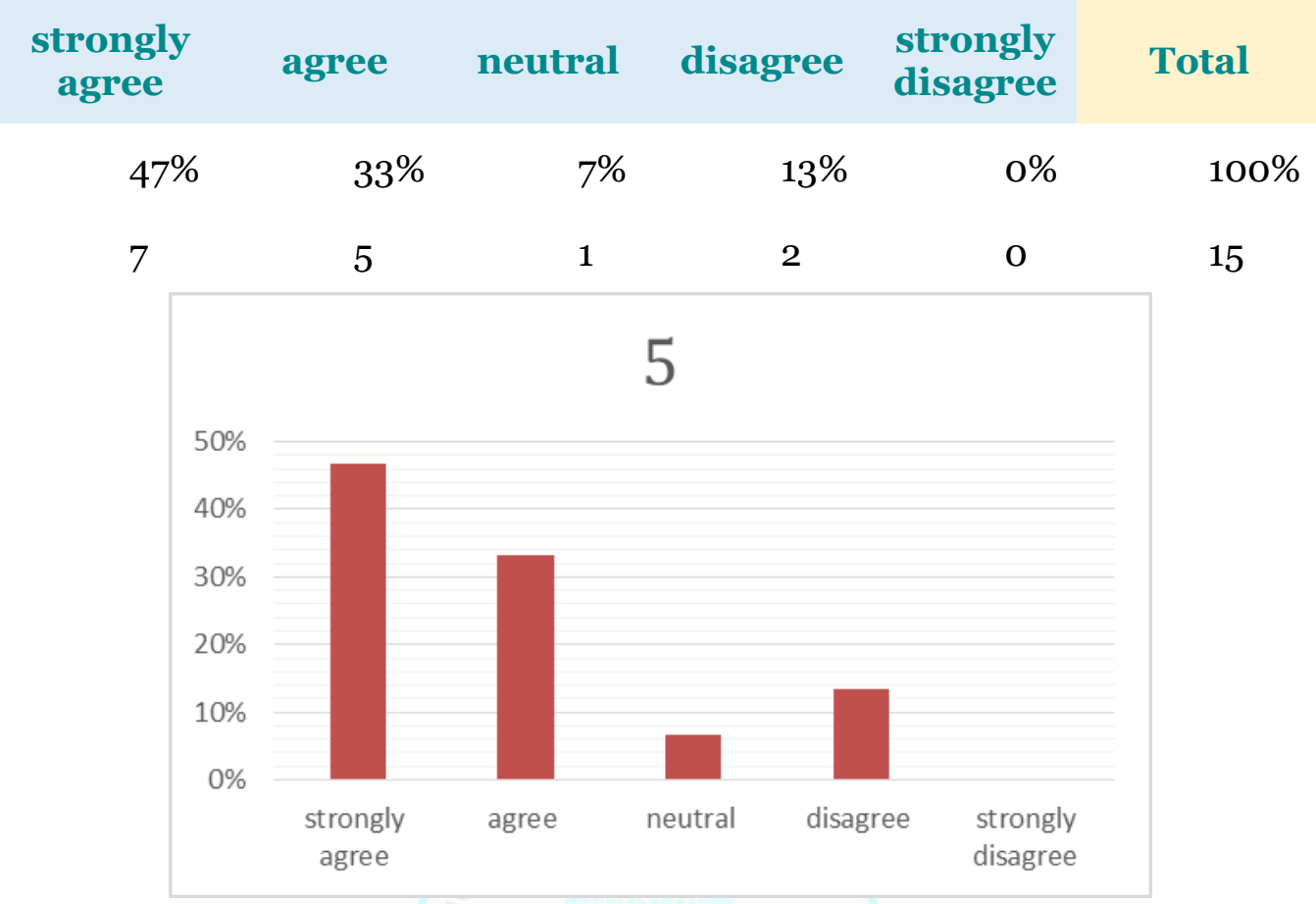

More than 50\% agrees or strongly agrees that someone on staff is responsible for resource management. This suggests that there is bias in resource management of the school which can compromise quality.

6. Organization has a written personnel policy that is regularly reviewed and updated.

$\begin{array}{cccccc}\begin{array}{c}\text { strongly } \\ \text { agree }\end{array} & \text { agree } & \text { neutral } & \text { disagree } & \begin{array}{c}\text { strongly } \\ \text { disagree }\end{array} & \text { Total } \\ 27 \% & 40 \% & 7 \% & 20 \% & 7 \% & 100 \% \\ 4 & 6 & 1 & 3 & 1 & 15\end{array}$

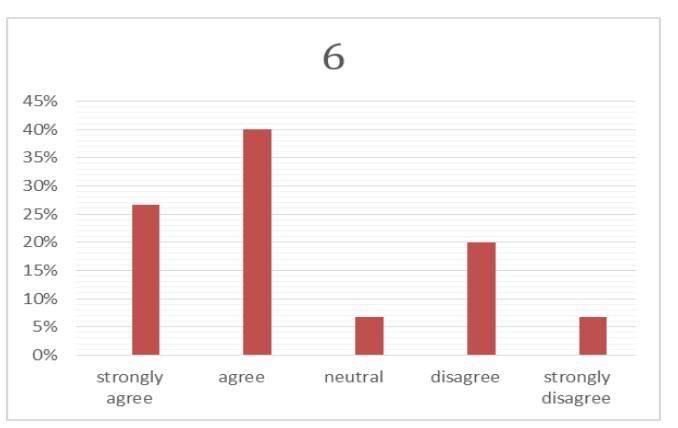


More than $60 \%$ agrees or strongly agrees. This means that the organization maintains and reviews a written personnel policy. This provides a basis or criteria for assessment for compliance with these policies.

7. Employees receive appropriate orientation and training.

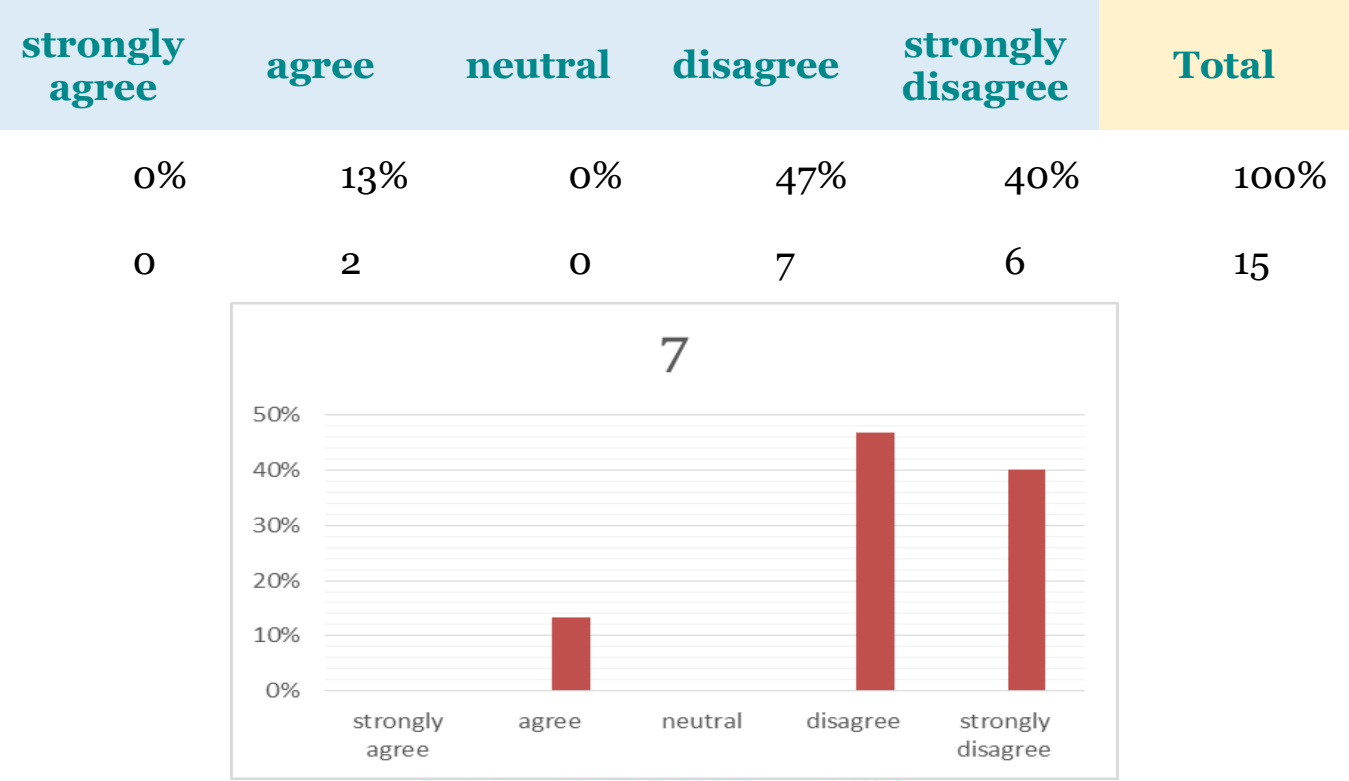

More than $80 \%$ of the respondents disagree or strongly disagree that the employees receive appropriate orientation and training. Lack of orientation and training can compromise the quality of service offered by the employees.

8. Employees are educated and periodically updated on benefits and resources available to them.

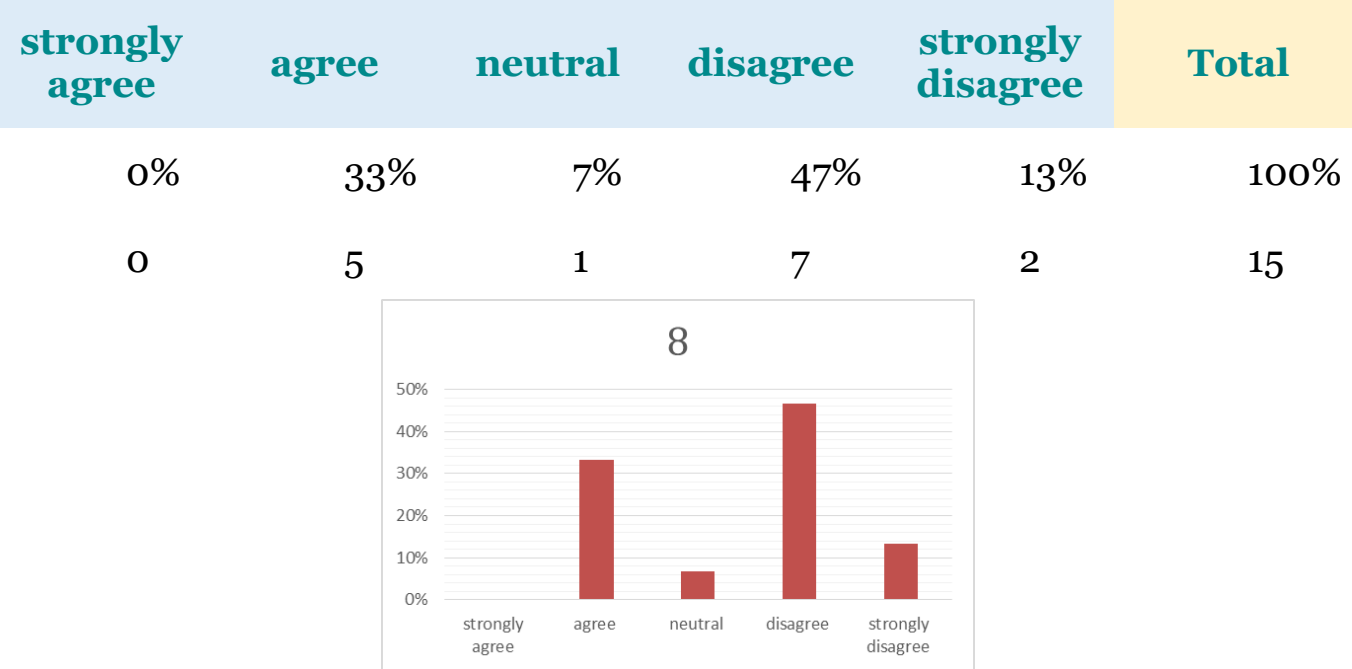


$60 \%$ of the respondents disagree or strongly disagree that employees are periodically educated and updated on resources available to them. When employees are not educated and updated on resources available, there might be system errors and low usage of available resources thus affecting delivery of services.

9. Each employee has a job description that accurately reflects their duties and expectations.

\begin{tabular}{|c|c|c|c|c|c|}
\hline $\begin{array}{l}\text { strongly } \\
\text { agree }\end{array}$ & agree & neutral & disagree & $\begin{array}{l}\text { strongly } \\
\text { disagree }\end{array}$ & Total \\
\hline $0 \%$ & $13 \%$ & $7 \%$ & $27 \%$ & $53 \%$ & $100 \%$ \\
\hline \multirow[t]{2}{*}{ o } & 2 & 1 & 4 & 8 & 15 \\
\hline & & $\begin{array}{rr} & \\
60 \% & \\
50 \% & \\
40 \% & \\
30 \% & \\
20 \% & \\
10 \% & \\
0 \% & \\
& \begin{array}{r}\text { strons } \\
\text { agre }\end{array} \\
\end{array}$ & $\square_{\text {agree }} \underset{\text { neutral }}{\square}$ & $\underbrace{}_{\substack { \text { disagree } \\
\begin{subarray}{c}{\text { strongly } \\
\text { disagree }{ \text { disagree } \\
\begin{subarray} { c } { \text { strongly } \\
\text { disagree } } }\end{subarray}}$ & \\
\hline
\end{tabular}

$80 \%$ of respondents disagrees or strongly disagrees that employees have clear job description. Unclear job descriptions make it difficult to evaluate the performance of individual employees. 10. Employees clearly understand which staff members are responsible for managing them.

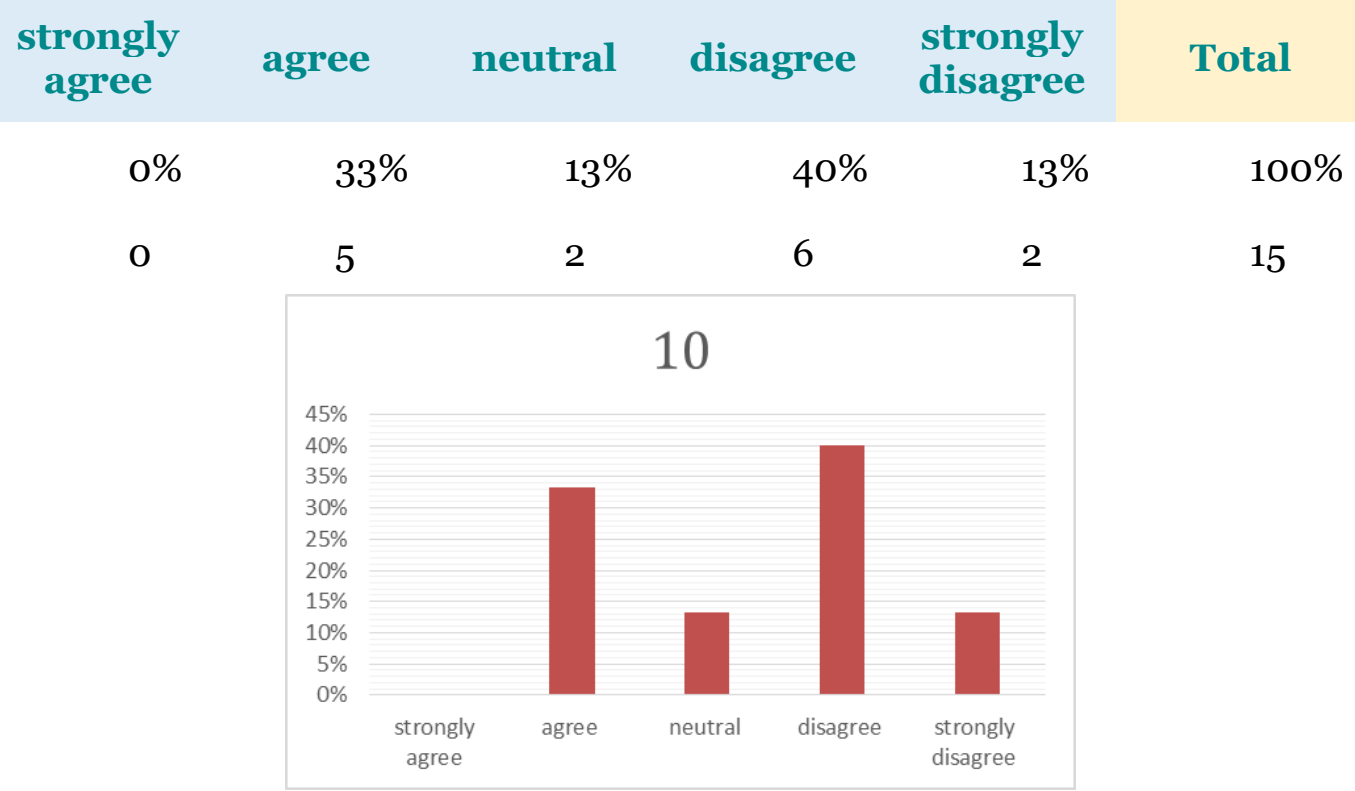


Most respondents agree or strongly disagree that employees understand which staff members are responsible for managing them. This might cause confusion in management and creates ambiguity in management supervision and employee reporting.

11. Employee performance reviews are conducted and documented at least annually; and pay raises and opportunities for advancement are linked to accomplishment of strategic objectives.

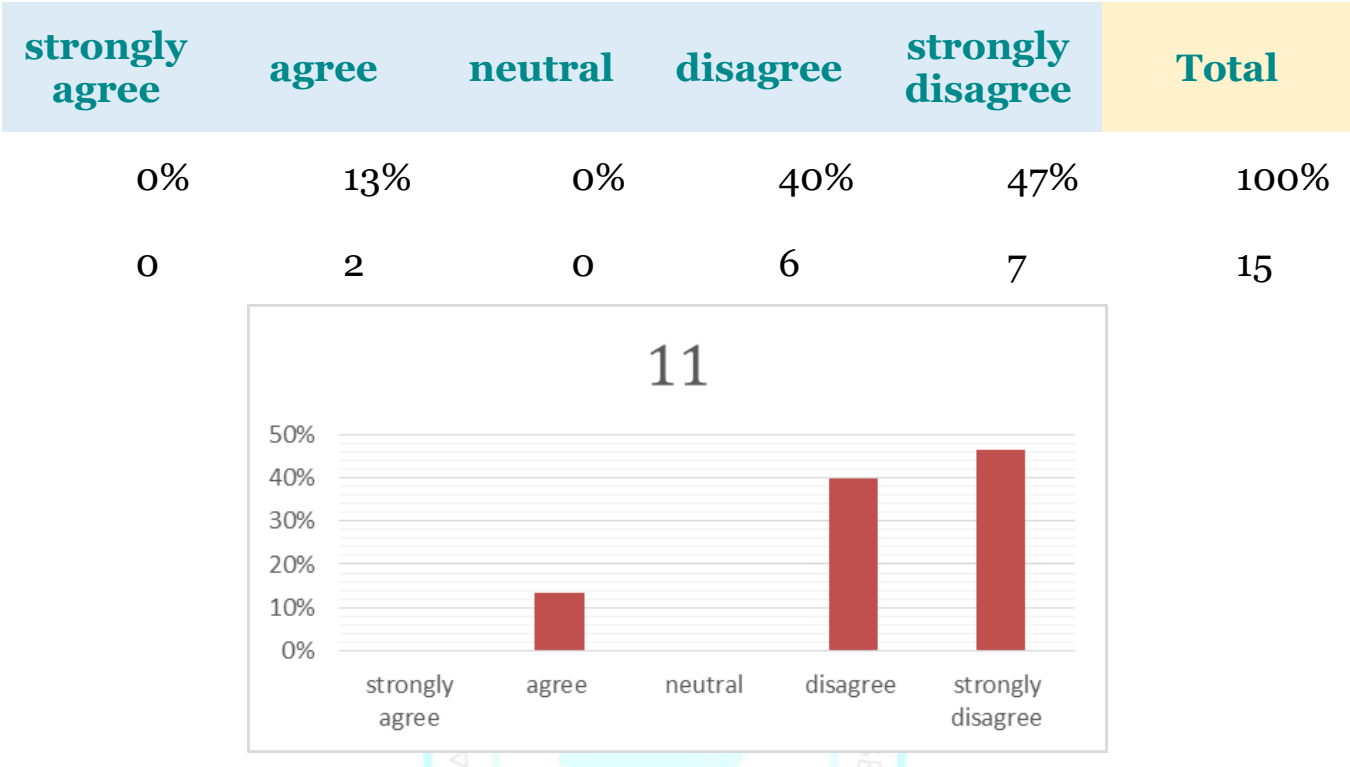

$87 \%$ of the respondents either disagreed or strongly disagreed that performance reviews, pay rises, and opportunities for advancements are based on achievement of strategic objectives.

12. Employees are appropriately compensated: competitive salary, health benefits, leave time, or retirement plan.

\begin{tabular}{cccccc}
$\begin{array}{c}\text { strongly } \\
\text { agree }\end{array}$ & agree & neutral & disagree & $\begin{array}{c}\text { strongly } \\
\text { disagree }\end{array}$ & Total \\
\hline $0 \%$ & $13 \%$ & $13 \%$ & $53 \%$ & $20 \%$ & $100 \%$ \\
0 & 2 & 2 & 8 & 3 & 15 \\
\hline
\end{tabular}




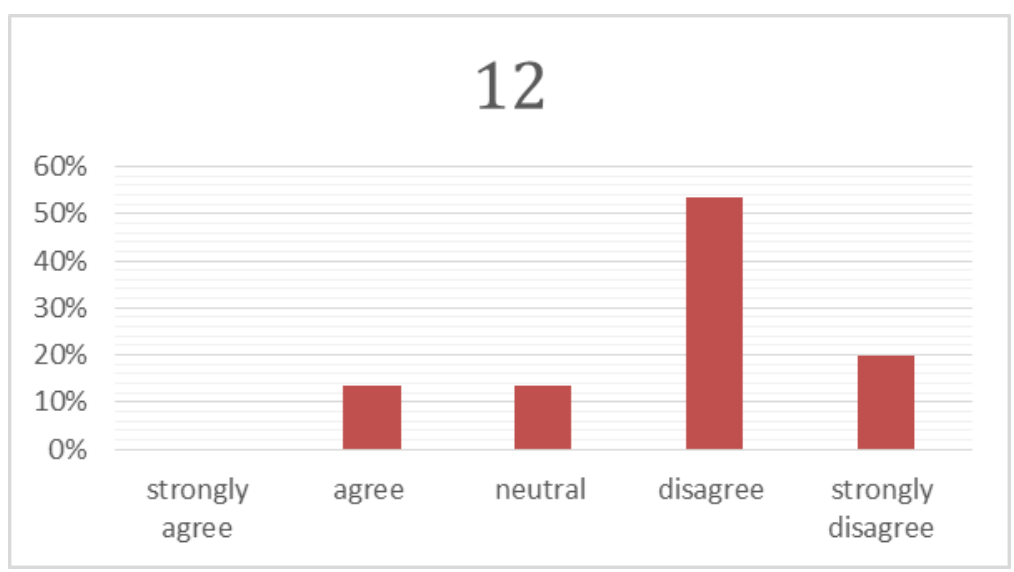

Most of the responses, $73 \%$ either disagreed or strongly disagreed that employees are appropriately compensated. This means that employees are not compensated well hence lack motivation.

13. Salaries and payment of artists, humanists and scientists is consistent with industry standards.

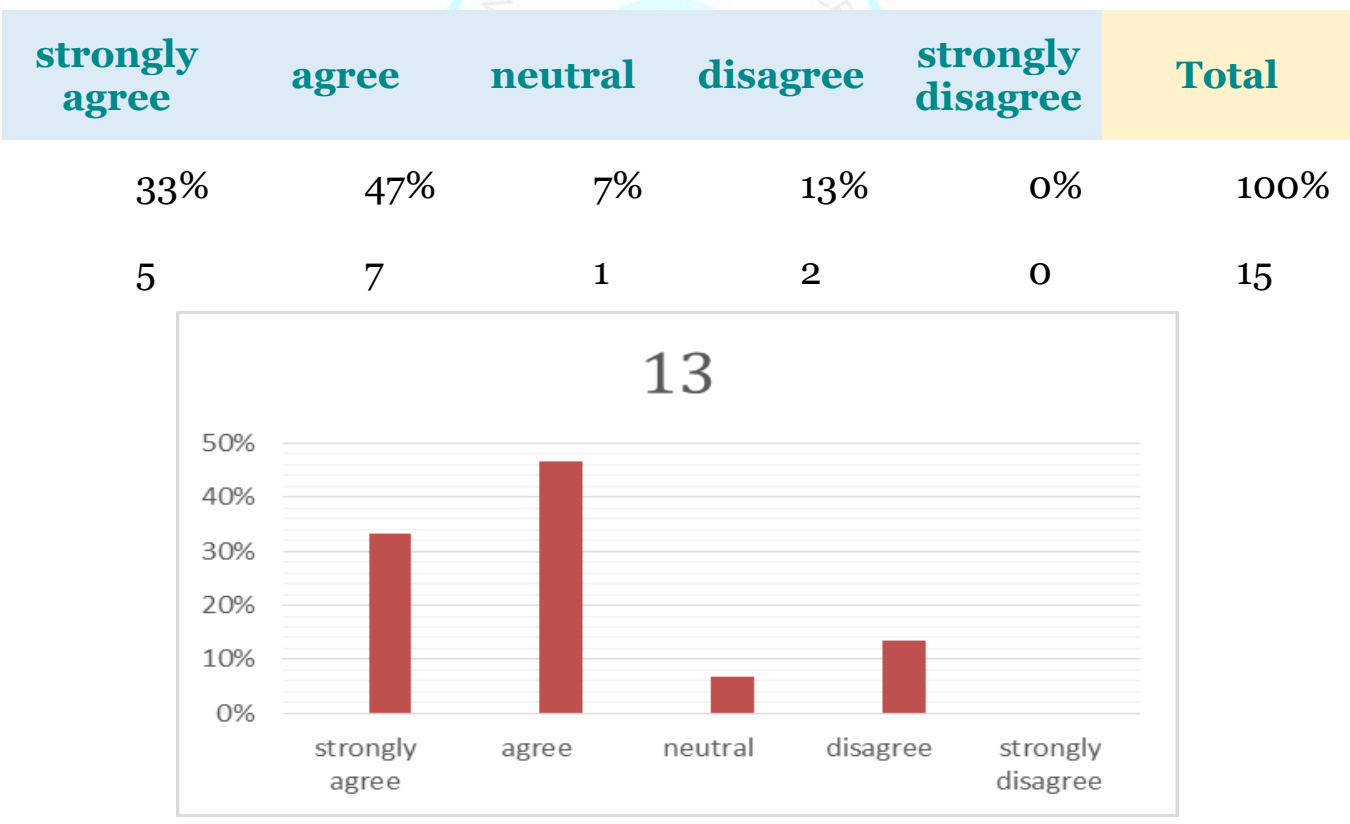

Up to $80 \%$ of the respondents either agreed or strongly agreed with the statement that scientists, humanists, and artists are paid consistently with industry standards, which is a good policy.

14. Employee turnover is well managed so that organization's operations do not falter. 


\section{Asia Pacific Journal of Contemporary Education and Communication Technology \\ ISBN (eBook): 9780994365682 | ISSN : 2205-6181 \\ Year: 2017 , Volume: 3, Issue: 2}

$\begin{array}{cccccc}\begin{array}{c}\text { strongly } \\ \text { agree }\end{array} & \text { agree } & \text { neutral } & \text { disagree } & \begin{array}{c}\text { strongly } \\ \text { disagree }\end{array} & \text { Total } \\ 0 \% & 13 \% & 7 \% & 53 \% & 27 \% & 100 \% \\ 0 & 2 & 1 & 8 & 4 & 15\end{array}$

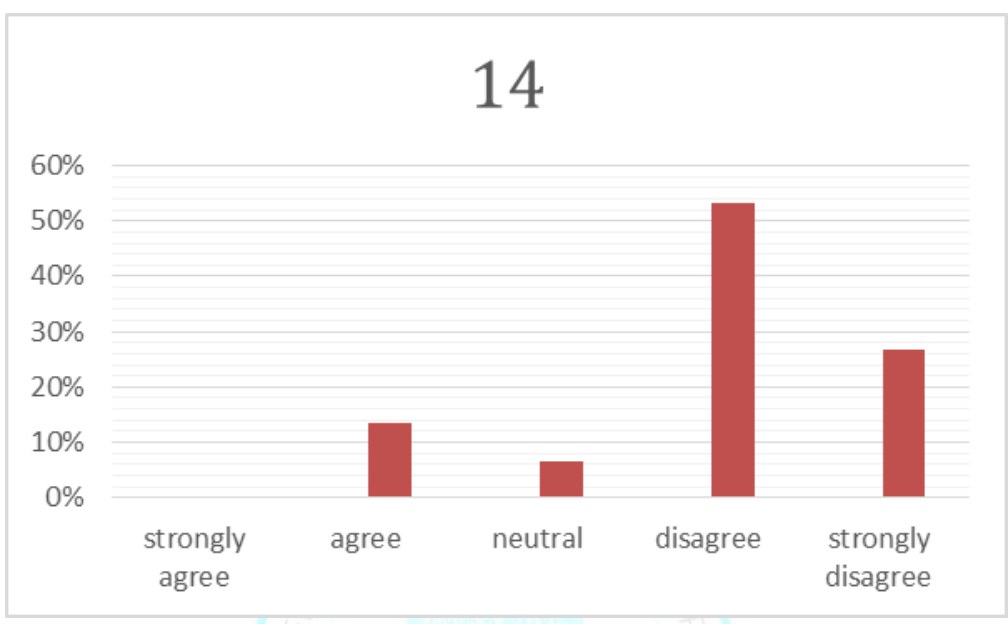

$53 \%$ of the respondents disagree while $27 \%$ strongly disagree with the statement. This means that the school does not manage the employee turnover hence falters operations.

\section{Results}

Regarding theme two (Human Resources), I found that the school's management of its human resources is poor. The school has human resource policies that allow loopholes for recruitment of unqualified or less qualified employees thus affecting quality of service offered. The school does not motivate its human resources; the employees are inappropriately remunerated, denied adequate leave times, and do not adequately enjoy other benefits. Less motivated employees perform below standards and hence may lose the goodwill to help the school accomplish its strategic objectives.

\section{The Model applied (ADDI model)}

Various models may have been used but for this project, the ADDIE model most suitable. It was originally designed in the 1970's for the United States army by the Center for Educational Technology in Florida State University. It is an acronym for the development programs that include design, development, implementation and evaluation. The first stage in the model is the analysis phase and it identifies and addresses the need for training. The second phase is design and it involves planning of the training program. The third phase is development where the program is developed which is followed by implementation where the training is implemented into the field. Last is the evaluation phase which assesses if the overall training program was effective in achieving the goals and objectives that had been set (Danks, 2011). I opted to use this model because it is effective in promoting effective learning through training and it has been used by a lot of professional trainers which enhances its validity. 


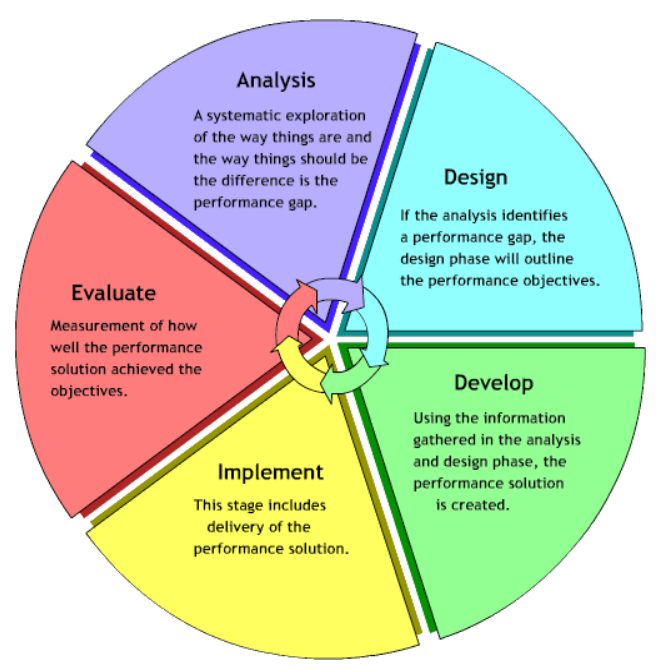

ADDIE Model: Phase 1 Analysis

\section{Needs analysis}

\subsection{Overview}

In ADDIE model we will go through five steps to conduct the needs assessment. Need analysis phase is the first stage in training process which involves the process of identifying the organizational performance gap. It is the phase where researchers collect data and information to determine whether training will be the solution to the identified problem before implementing the actual training program (Hamberg, 2002). It is also where the skills and existing knowledge of the learner and the learning environment are identified. Here, assessment is done to determine whether training will help to resolve the identified problem before starting on the design or delivery method. It requires a lot of research to gather all the information that will be used to determine the best approach to resolve the problem identified.

The problem related to high employee turnover could be as a result of various reasons such as the state of the economy, stress, poor supervision, monotony in the workplace, poor channels of communication and inadequate training. The problem at Ajaad School is attributed to lack of orientation for new employees which creates problems for them since they are not given their job specifications and what is expected of them.

\subsection{The problem raised}

Ajaad School faced the problem of a continuous employment process to replace the employees who had left. Lack of employee retention created various problems for the school. The school kept incurring costs for recruiting and hiring new employees. There was a lot of time wasted during the hiring process and this had negative consequences especially to the school's program. The most severe consequence however was the effect hiring new employees had on the students. Since it took long periods for the new employees to catch up with the school program, they were unable to offer the best quality education during this time. As a result, the continuous employment greatly affected the students and their school performance. The question thus 
raised is; what is the cause of the high employee turnover at Ajaad? Can this problem be resolved?

\subsection{The techniques used}

My choice for documenting this analysis is based on the goal that I want to achieve. To do so, I decided to use three techniques namely observation, interview and document analysis. I believe that this tools are best suited to assess the problem at the school, identify where the problem originates from and come up with ways of eliminating it to prevent it from affecting the school's performance and reduce the rate of employee turnover.

\subsection{Observation}

I have worked in the school for a period of one year and while there, I have observed that the employees are dissatisfied with the school and their work. Employees are constantly complaining that they do not fully understand their job description and are not sure of the best approaches to take so as to accomplish their duties. This makes it difficult to perform their duties because they lack a clear guideline of what is expected of them and how to resolve any issues that may arise (Brum, n.d). Lack of supervision also deters their will to work as they view the organization as not caring and ignorant. As a result, there is a high turnover rate because the employees are dissatisfied and jump at the opportunity of finding employment elsewhere. The reason for using observation is because it is the best way of collecting primary data. The goal was to gather firsthand information from the employees of how they view their work environment and I achieved this through engaging them in conversation discussing various work related topics.

\subsection{Interview}

In this section, interviews were conducted face to face on five people in order to understand the reason behind the high employee turnover at the school. The interviewees were; Noorah AlSahlee who is the school principle, Walaa Talat and Ikram Mohammed who were supervisors and Amal Rahseed and Intisar Al-Salamn who were the female and social supervisor respectively. They were all asked a set of three similar questions (refer to appendix section) whose aim was to identify the cause behind the high employee turnover within the school. The reason for using the interview is because it is a good way of getting people's opinion and collecting data. The goal was to get the participants opinion of what could be the cause of the high turnover rate and I achieved this through a set of three questions posed to the interviewee's. The interview can be found in the Appendix

\subsection{Document analysis}

I analyzed the vision, mission, goal, objectives, job specification at Ajaad School, I found that even though the goal is to equip the students with the skills and knowledge they need so as to be able to participate in a global community with integrity, they fail to acknowledge the importance of employee training and orientation. As a result, the people given the task of meeting this goal often lack the skills and knowledge to accomplish their tasks. The difficulty they face makes the working environment unconducive which leaves the school vulnerable to employee turnover. I chose this method because it is good for retrieving background and secondary information. The goal was to retrieve previous data and compare it to more recent data to better understand the rate of employee turnover in the school. 


\section{Results}

I found a pattern that cut across interview, observation and document analysis which revealed a deficiency in proper training of new employees. Lack of orientation training meant that employees were unaware of their job descriptions, their duties and what was expected of them. As a result, the employees found it difficult to accomplish basic tasks, were dissatisfied with their work and the company and this greatly affected their performance. Lack of orientation training was thus the cause for the high employee turnover in the school.

\section{Literature review}

Employee turnover is the frequency at which an organization hires new employees to replace the ones who have left. It is the duration at which employees stay within the organization before shifting to seek employment elsewhere due to various reasons. When there is a high turnover rate, an organization may experience various challenges such as a change in the quality of production, reduction in the level of performance and incurring heavy cost needed to recruit and train new employees (Huckman \& Ton, 2008).

High turnover could be caused by various reasons among which is; lack of supervision, employee dissatisfaction with their jobs, lack of required skills, poor working environment or lack of orientation training. The problem can however be solved through proper orientation training. Through training, employees will be informed of what the company expects of them and what must be done when performing their duties. It also equips the employees with the skills and knowledge they need to understand and perform their duties thus ensuring they are comfortable in their working environment (Huckman \& Ton, 2008).

In his article "what impact does training have on employee commitment and employee turnover?" Scott Brum argues that training can have positive effects on the success of a company and enhance employee retention. He further argues that training can help an organization to save on cost required to recruit and hire new employees. Through training, a company is able to enhance the rate of employee retention. As a result, less money will be used to pay instructors, buying materials for training and to pay for supervision. This shows that if training is well implemented, employees will be more satisfied with their current employers and the organization will have less chances of employee turnover (Brum, n.d).

Brum further adds that employers often engage in activities to ensure that employees remain in their organization after they receive their training. This is achieved by implementing strategic training practices that create commitment to the organization. As a result, the organization is able to further decrease the rate of employee turnover. These commitment strategies are not only implemented during training but also through recruitment, during evaluation and during the employee selection process (Brum, n.d).

In the article 'employee orientation: keeping new employees on board', Judith Brown discusses the importance of orienting employees to their new places of work. Most organizations view orientation training as being boring and overwhelming and often opt not to do it. As a result, the new employees are less productive and generally confused and such an environment creates dissatisfaction that forces them to leave the organization after a short period of time. This shows that organizations that fail to conduct orientation training for new employees often have high rates of employee turnover (Brown, n.d).

According to Brown (n.d), organizations that have well-structured and implemented orientation programs have higher rates of employee retention and high rates of productivity. The 
orientation programs help the new employees to catch up quickly, creates an alignment between what the employees perform and what the organization expects from them and also has low rates of employee turnover. The employees are aware of the operations conducted within the organization, their duties and what they are required to do so as to meet the objectives set. They are more satisfied with their working environment and are less likely to relocate to other organizations thus reducing the level of employee turnover (Brown, n.d).

Shelby Danks' article titled 'the ADDIE Model: designing, evaluating instructional coach effectiveness' discusses the process that an organization can engage in to train its new employees (Danks, 2011). It addresses the role that instructors are required to play so as to offer the best training. It also acts as a means of evaluating the success and effectiveness of the methods implemented to check if they were able to meet the goals and objectives set at the onset of the training program (Danks, 2011). In the case of orientation training, the model can help the instructor in determining the best approach and implementation of the training program. This will increase the program's rate of success and enhance its role in reducing the rate of employee turnover.

\section{Results}

From the three tools used for research, I discovered that the most prominent factor that leads to high employee turnover is lack of skills and knowledge as it leads to dissatisfaction with the working environment. The information collected supports the secondary data which suggests that lack of proper training denies the employees with the skills and knowledge needed to accomplish the tasks assigned to them (Brum, n.d). The similarities between secondary data and the information I collected can thus be used to support my findings and use orientation training as the ideal method of reducing employee turnover in an organization.

\subsection{Training}

Training is defined as the systematic process of developing the skills, knowledge and capabilities that individuals require in order to complete tasks satisfactorily. It is a planned learning experience that gives employees the skills and knowledge of how to accomplish the tasks that are involved in their job description (Brum, n.d). Training is therefore important to both the employees and their organization as it plays a big role in enhancing the quality of their performance.

Some of the training is compulsory as it is set as a requirement by the Occupational Safety and Health Administration. This includes training in areas related to the health and safety of employees at their places of work. The employer is responsible for limiting the assignment of certain jobs only to people who qualified or have had previous training as is stipulated by the standards set by the Occupational Safety and Health Administration. This shows that training is of great importance as it assists in guaranteeing the employee's health and safety by equipping them with the skills and knowledge they need to protect themselves from illnesses and accidents that may occur in the workplace (Huckman \& Ton, 2008).

Other types of training are voluntary and it is the organization that decides on the most appropriate training for its employees. This may be done either through on the job or off the job training. On the job training involves training employees as they perform their daily duties. Those that are being trained are engaged in an actual work scenario. They are required to perform their duties under the supervision of their trainers who assess their ability to perform 
their duties and offer guidance (Bax \& Glebbeeck, 2002). In the case of off the job training, employees are trained away from their working environment. Employees are trained at workshops or seminars where they are given guidelines or demonstrations of how they are expected to perform their duties. This method is however expensive and is only used when short periods are given to train large number of employees (Brum, n.d).

Regardless of the type of training method used, training has a lot of benefits if well conducted. It is a good way to identify and deal with employee's weaknesses. The various training programs help employees to strengthen the skills that they may find challenging to accomplish. It also groups employees together where they learn to work together and come up with ways of enhancing their quality of work. Instead of relying on each other, the employees learn to work together to accomplish a specific task. Training thus creates an environment where employees can work together or as individuals without the need for constant supervision (Brum, n.d).

Training also helps to improve the employee's performance and quality of work. The employee is equipped with the skills and knowledge of their job descriptions and the best approach that will result to the best performance. The employee learns the procedure for performing basic tasks within the organization and to observe safety practices. The knowledge builds confidence because they have a better understanding of their duties and the organization which encourages them to be more resourceful and come up with ways of improving their level of performance. Through continuous training, employees are kept up to date with the trends in the industry and are able to implement these skills to enhance their performance (Brown, n.d).

Orientation is a form of training that assimilates the new employees to the organization environment. It give the employees an idea of the organization's history, culture, vision and what will be expected of them after joining the organization. Orientation thus acts as the beginning of the socialization process as the employees learn of the operations within the organization. Orientation training may be short, one day, or extend longer, a week or so, depending on the nature of the organization. Regardless of the time, it is important as it helps to communicate the organization's expectation to the new employees. The organization may use this platform to communicate the rules that the employees are expected to follow while performing their duties. Doing so will help enhance the work performance and reduce disagreements since the employees have a set of rules to follow (Huckman \& Ton, 2008).

Orientation training can also be used to inform the employees what the employer intends to do for them to take care of their needs as its employees. This creates a sense of care that boosts their morale which reduces the rate of employee turnover in the long run. Employees who view an organization as caring and attentive to their needs tend to be more satisfied and less interested in relocating to other organizations (Bax \& Glebbeeck, 2002). Orientation training also helps to reduce employee turnover by informing employees what opportunities are available if they stay with the organization. This includes informing them of teaching new skills, assignment of new responsibilities and various job promotions. The organization can also discuss the various ways it intends to reward its employees and recognize those who perform exceptionally well and their reward. Orientation may also help employees feel like they belong by informing them of the organization's culture and operations. This makes them view their work as being meaningful and important which motivates them to work harder to meet the set objectives (Brown, n.d). 
7.2 Training as a way of enhancing employee retention at Ajaad School

Employees often leave their current place of employment for various reasons among which is dissatisfaction with their current employment, they may lack the sense of belonging, find it difficult to accomplish their tasks or have been offered a better deal elsewhere (Brum, n.d). For this reasons, it is important to ensure that the needs of employees are met and that there a conducive working environment. Various attempts could be made to encourage employees to stay and reduce the high turnover rate at Ajaad School. Training is the most ideal as it is able to address and resolve most of the issues that lead to employees moving to other organization (Huckman \& Ton, 2008).

Through training, employees get a sense of belonging, they learn to work with others and work as a team. Training also equips employees with the skills they need to perform their duties satisfactorily and with less levels of difficulty. They will thus enjoy doing their work and be happy with the end results. Training also facilitates learning of the organization's culture and this makes the employees feel as they are part of something big (Brum, n.d). Employees who are satisfied with the organization may find it difficult to leave even when offered a better deal because they feel part of their current place of work and opt to stay.

Training new employees will help them learn how the school is run and its values. They will thus learn and adopt its policies and practice them in their daily activities. They will also learn what is expected of them as the school's employees, its history, the culture and the strategic vision of the school at large. Training therefore plays a big role in enhancing employee retention and protects the school from all the disadvantages brought about by high rates of employee turnover (Brum, n.d).

\subsection{The aim of the training program manual}

The aim of the program is to reduce the rate of employee turnover at Ajaad School through orientation training. This will help to reduce job tardiness as it will facilitate increased job satisfaction, better understanding of employee's roles and thus improve their job performance. High rates of employee have negatively affected the students and their school performance. The high turnover rate is as a result of the tardiness and poor understanding of employee's roles and responsibilities. As a result, employees are less satisfied with their jobs, are less motivated to perform well and are always looking for better opportunities and often leave when they present themselves. The school thus suffers from high employee turnover with the effects extending to the students.

\section{Limitations}

The main focus of this study is to show the impacts that orientation training has in reducing employee turnover. It is however dependent on the willingness and attitude of the employees towards the training. The training will only be successful if the employees have a positive attitude towards the training and are willing to follow the guidelines stipulated in their daily activities. If the employees are unwilling to participate, there will still be a high turnover since they will fail to grasp the concepts intended regardless of the nature of the training program.

\section{Conclusion}

I found so many factors behind the high rate of turnover in the school, but I choose the lack of orientation because it make a different in my school. Employees often complain that they are not aware of their job descriptions and they are unable to fulfill their duties since they lack the 
necessary skills and knowledge. The high rate of employee turnover in Ajaad School is attributed to the lack of orientation training when hiring new employees. This can be resolved through proper training and orientation training to ensure that employees are able to meet their tasks and are satisfied with the organization they work in thus enhancing employee retention.

\subsection{Design phase}

Based on the findings of the analysis phase I decide to develop an orientation training program. Before I start designing the training program I will identify the audience and what their leaning style is. In order to explore the employees learning style I conducted learning style inventory (survey). In fact this step enlighten me to choose the instruction learning theory.

\subsection{Audience and learning style}

The approach to learning may take various approaching depending on the complexities of the ideas to learn and also the learners. Many scholars have advanced their versions of learning and styles that the learner's ability can get evaluated. The program focuses on the educational sector's employees as the target audience. Numerous factors may affect the learner's ability and autism is one of the most detrimental learning inhibitors. Learning style inventory aids in coming up with relevant and sound conclusions regarding what method of learning the trainees are comfortable with and the reasons behind preferences (Veres, et al., 2011). The learning style inventory approach incorporates the designing of a questioner with open-ended and rigid questions. It is a kind of survey that ensures that learners choose only the answers that tend to please them firmly while leaving the rest as outlined by the questioner. They have to think critically the repercussions of each choice they choose due to the consequences that may follow during the implementation of the learning style they plan to adapt.

The application of the learning style inventories plays a core role in making any future anticipation and development of the educational curriculum (Kolb, 2013. The IQ of learners is very different as well their diligence whereby in most cases it gets influenced by the environmental factors that one gets exposed to and also the parents cognitively. Social-cultural factors may at times impact on the style that the instructor may embrace to his learners and ensure a rhythmical flow of ideologies and development of important learning ethics. Learning style inventories provides that strategists better fit the students with the styles that better suits their needs and can encourage healthy growth and development of an informed society. Theorists since 1970 have been embracing the notion that different people possess different styles of learning, and the predominant style mostly defines the style that one acquires that the learner got exposed to during the early stages of learning. The learning style inventories get geared towards ensuring that the students learn regarding their strengths. The survey plays an important aspect in winnowing out the undesired learning techniques that teachers may use to their students and may end up adding no value. The approach has helped to a great extent in the strengthening and making education of different categories of learners is of help in line with their expectations and goals.

The simple learning styles in existence include, auditory, tactile and visual. Some individuals usually employ one method while others use a combination of methods. According to Ellis \& College Survival, Inc (2003), the learning style inventory is typically designed to enable respondents to be able to determine their learning style.

For auditory learners they will wish to utilize tapes. By employing tape lectures, they find it comfortable to replace gaps that could be present in notes. Additionally, they do take notes, 
listen and frequently review notes. During lectures, they position themselves strategically to be able to listen well. They usually recite something aloud after they have summarized something that they have read. For visual learners, they usually look at the materials of study. Use filmstrips, maps, charts, flashcards and notes. Practice picturing or visualizing concepts or words in their heads. Ensure that they have written out everything to assist them in quick and frequent visual review. Ellis \& College Survival, Inc. (2003) argue that tactile learners usually trace words during their presentation or mention. They ensure they write down several times facts that should be learned. For its purpose, they ensure they have kept the scratch paper. They make study sheets and keep and usually take notes.

Therefore a learning style survey was carried out to 15 of the employees and it was evident that each of the employees had distinct learning style that was quite a reasonable finding to in the survey. The study showed that out of the 15 candidates of the survey, most of the candidates were able to use the exact type of learning where they read and wrote they ideas on paper as most of the employees were well educated and had no major disorders that could interfere with either reading or writing. Therefore questioners were offered to the employees and they were able to fill them adequately training

However a good drill design will have to involve mostly all the kinds of training procedures required to capture and to allow the trainees needs are well met hence allowing satisfaction to the trainees. Thus to ensure comfort it is of importance that different kinds of multi-sensory learning styles are incorporated to ensure a higher chance of appealing to the trainees hence helping reinforce the knowledge and skills acquired

\subsection{Learning theory}

Two main theories fit to this situation and important in HRD. First, adult learning theory. Second, engagement theory.

\subsection{Adult learning theory}

Adult learning theory serves as the basis for any type effective training program, and new employee's orientation program should be no exception. The adult education theory refers to a concept as to how adult beings learn and it is quite different from the child learning theory as there are many differences on how adults and children behave. Andragogy as Malcolm Knowles refers it in his book of The modern practice of adult education is a theory that describes how the adult education should be conducted and explains the understanding of the adult mindset to carry out practical training to the adults. To achieve a practical education to adults there are assumptions that facilitate the process, the include the self-concept that explains the maturity of adults to become more self-directed. Moreover there is experience whereby adults have different kinds of experiences that provide excellent resources for learning, adults also are much more ready to knowing the areas relevant to their current job, there is orientation to learning, motivation to learn and the relevance of the education in their routine activities outside the job.(teachinglearningresources.pbworks.com, 2015)

Adult learning theory is quite a crucial aspect when it comes to training employees as it requires the application of the knowledge to facilitate a good drill to the trainees who are adults. Therefore this theory is very beneficials when it comes to training adults as it provides a good understanding of the adult mindset and what they expect thus enabling coming up of existing training protocol purposely for the adults. 
9.6 Engagement theory

It is one of the current theories that most instructors have to end up in adapting due to their relevancy and ability to generate meaningful outcomes. The theory is a going concern process and not an event since it ensures that the learning parties fully participate in the learning exercise. The facilitator to use this approach since it incorporates series of activities that get tailored towards providing active learning. It ensures that learning starts from observation, discussion, presentation/teaching and finally articulation of the scientific ideas into daily ritual practices. The theory encourages self-determination and in the learning arena teachers will get an opportunity to choose the subjects that best suit their capabilities and think can perform best. The administrators will, in the same way, get assigned roles and duties that will result in them enjoying their work.

The approaches of this theory are close to those of intrinsic motivation (IM) that gives meaningfulness, competence, choice and progress a core role towards increasing the worker's morale. The theory aims at achieving learning, skill development and creation of a pool of knowledge towards the end of the learning exercise (Billett, 2014). The instructor will ensure a complete adoption of the engagement theory by making sure that the selected group of trainees gets related to the tasks and chores of interests and have competencies as a way of encouraging learning. Similarly, encourage them to learn the ideologies continuously through the free environment and associations. The employees will, therefore, be expected to get vigilant and persistent while committing themselves to the tasks assigned. They will play a prolific goal because of the value that they attribute to work. Application of this theory will ensure the employees in the faculty education experience a tremendous improvement in their learning skills and knowledge.

\section{School constraints}

Some of the constraints that are present in the school include time available for the training to be delivered since the schools employees are usually busy. Additionally the technology level in the school as it will dictate how quickly and efficiently the schools employees can be helped in learning.

\subsection{Mission}

"The mission of the training program is to equip the employees with appropriate skills and relevant knowledge regarding the education sector. This will later get transmitted to the learners through learning thereby improving the quality of teaching at a global scope a way of actualizing 2030 strategic plans".

\subsection{Vision}

"The vision of the training program to create a revolution in the education sector and ensure learners gets opportunity to practice tasks that they have interests and competencies"

\subsection{Training program objectives}

Training learning objectives describe the purpose intended and the results expected in the activities of training. They are usually clear statements that are brief and stress on the learning outcomes desired.

The training program will aim at making a change in the perspective of people's minds. It will work towards eliminating an undesired disparities and encourage workers to participate actively in activities that are within their scope. These will be the main objectives of the program within the 1-day orientation of the trainees. 


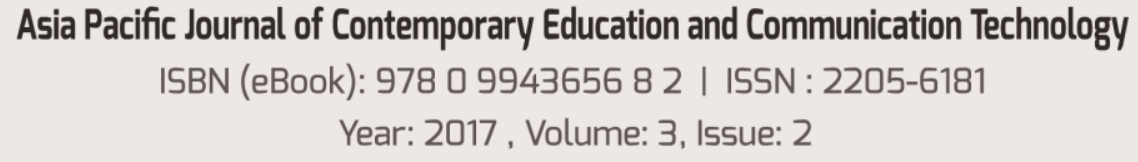

- To ensure that the quality of skills acquired by employees create a positive impact in the education sector.

- To discourage the prevalence of coercion as well as cultural differences in the learning sector by creating a universal platform of work ethics.

- To ensure that new workers in the environment find it hospitable and quickly adapt to the learning systems within the shortest time.

- To psychologically enable the workers in the teaching sector ready to admit any technological changes adopted by the ministry aiming at making teaching favorable.

\subsection{Learning outcomes}

At the end of the learning program, trainees are expected to experience a significant growth in the varsity of skills and knowledge. According to Shumway, (2013) the strength of the outcomes is defined by the quality and the level of training that workers have got exposed to both in the short and long run. After the training program:

- The employees will be able to notice a change in their work execution capabilities. The outcomes of learning should encourage future adoption of the made styles.

- Cultural differences should get harmonized, and workers should find it comfortable in accepting the other person's way of life and create an enabling working environment The training will ensure that new workers easily get articulated in the already existing workforce. The training shall lower instances of work discomforts and other discomforts that may arise.

- The training program shall enlighten the entire teaching sector and make it aware of the changes that may arise due to technological advancements over time. They shall get prepared to adopt any new system geared towards making the learning exercises an easy task.

\subsection{Factors that facilitate learning}

Baylor \& Ritchie, (2012) argue that learning is a process that relies on the learners ability to integrate various issues. The commitment and zeal to drive one's efforts towards ones achieving the outlined conditioned by the motivation and enthusiasm a learner inputs.

The tone of the instructor also contributes to one's willingness to learn as unfriendly and abuse language will stand at shying away the learner. The environment that a learner gets exposed to also plays a significant role in determining the level of learning. Repetitive practicing of the learned idea incorporates an aspect of conditioned reflex action and the outcome during the execution stage is likely to become high.

Alternative methods of learning such as lecture, demonstration, practical exercise and controlled PE can also get embraced in learning avenues. All these methods gear towards ensuring the required knowledge and skills gets transmitted from the source to the target group.

\subsection{Development Phase}

The development process is an involving procedural step that includes the production of the relevant material that will be useful and handy in the training, orientation and employee absorption in the schools (Courtney, 2009). As discussed earlier, the main factors that lead to new employee displeasure are as follows: lack of supervision, employee dissatisfaction with their jobs, lack of required skills, poor working environment or lack of orientation training. Consequently, the development phase considers these factors and provides all the necessary means to avoid the occurrence of the employee discontent (Kingsbury, 2011). 
Input includes the elective instructional routines and the data identifying with learning help and exchange. The school's HR department that caters for the hiring of new employees should ensure that the recruitment process is free and fair to ensure that competent individuals are employed. The instructional methods that may be applied include,

\subsection{Lectures}

The new employees are to sit in class like situations and be addressed by the hiring managers, lower level managers and probably some of the experienced employees who would give them a firsthand experience of how to cope with the school's work schedules. Lectures are important since they ensure that the new employees are informed of the school's mission, vision, and goals (Kingsbury, 2011).

The lectures would be organized in the one school's halls that are not used frequently, and this would have to be done during convenient times to ensure that the orientation does not interfere with the schools program. The duration of the lecture will vary with the topics and issued being discussed; the lectures are not to exceed one hour to ensure that the employees are not exhausted from the long sitting hours.

\section{Demonstration:}

Presentation refers to the illustration and depiction of how the work is done. It includes taking the new employees to the respective places of work and showing them how the other employees do it. The demonstration significantly boosts the employee's confidence since it gives them a sense that they could also perform the assigned tasks (Kingsbury, 2011). For instance, new employees in the school's library should be taken for an orientation trip to the school's library and be shown how the duties are performed and possibly introduce them to the other employees who work in the library (Courtney, 2009).

\section{Practical exercise:}

The practical use involves the HR training managers involving the newly hired employees in realistic and related activities such as small tasks in the library; the new staff could be given the universities' Open and Application Catalogs and given little tasks of identifying particular books in the library. The practical exercises build the confidence of the employees and required attitude towards the schools working environment (Courtney, 2009).

\section{The Induction Process:}

The induction process embodies the strategies that are to be applied to the orientation of the new employees. The order of the process is the most significant factor in the development; the rule applied should ensure that the most important issues are addressed first then the less important ones should follow (Kingsbury, 2011). The timing of the activities should be done appropriately to ensure that everything is allocated enough time and the durations involved are sufficient enough for the new employees to grasp the content, process and schedules. Various methods should be used in combination to produce a hybrid approach that would suit the school's working needs, the listed methods above (Lectures and Practical exercise), should be used in combination to ensure that the best and most efficient orientation and training are conducted.

The output of the development phase is quantified and seen in the implementation phase.

\subsection{Implementation Phase}

The implementation Phase involves the actualization of the developed training and orientation strategies. The phase encompasses all the steps involved in training the new employees. A dry 
run is the first step in the implementation process. A dry run is the initial enactment of the training materials; a dry run may be conducted by an HR manager upon an existing employee to identify the strengths and weaknesses of the induction program (Kingsbury, 2011). The pilot testing follows suit and the first employees are taken through the training and orientation process. The results of these procedures are analyzed and reviewed; any misgiving of the process or any error that may be realized is rectified before another batch of employees is taken through the process (Courtney, 2009). The actual training is now undertaken having tested and ensured the training and orientation program is fit to induce and make the new employees comfortable with the working schedules and their respective working environments.

\subsection{Evaluation Phase}

It comprises of the evaluation of the strategy and design for the whole orientation process. The assessment phase is broad and objectively depend on the line and field of work; thus different areas have distinct evaluation processes and procedures (Courtney, 2009).

Two core types of evaluation include:

\section{Process Evaluation}

It establishes how well the whole training process achieved its objectives. The school's training program is aimed at orienting the new employees with the appropriate skills and positive attitude that will aid them in coping with the expectations of the management. Consequently, the process evaluation ascertains the degree of success of the training process and whether it adequately equips the trainee with the necessary skills.

\subsection{Outcome Evaluation:}

It determines the consequences of training on the intern; the training process is aimed at orienting the employee and making sure that they familiarize themselves with the working environment.

The trainees' duties and performance are also considered; how well the employee executes the tasks assigned. An effective training program equips the trainees with functional skills to enable them perform their duties with ease and correctly as expected (Kingsbury, 2011).

Consequently, the outcome should positively affect the school's mission and vision and make it easy for the school to attain its set objectives.

\subsection{Output of the training program:}

The process is evaluated and examined against the results obtained; this is done to check for any mistakes or factors that may affect the trainees. If shortfalls are discovered, it would be prudent to rectify or find other factors that would be useful.

The content delivered to the trainees is measured and determined if it's enough, some training programs do not deliver enough and helpful content to the employees, this aids the induction process and hampers the whole program leading to disgruntled employees. Inadequate employee training is a contributing factor of high employee turn- over (Courtney, 2009). The reaction of the employees should also be evaluated and examined if it conforms to the expected results. If not, appropriate rectification and correction should be done till the expected results are obtained (Courtney, 2009). The behavior of the trainees is also evaluated; positive behavior is expected if the training program is effective and efficient. 


\section{References}

i. Aajad School Mission and Vision, n.d. Aajad School Mission and Vision. [Online] Available at: http://www.aajadschool.com/MissionAndVission.aspx

ii. Aajad School, n.d. Aajad School Management Team. [Online] Available at: http://www.aajadschool.com/ManagementTeam.aspx

iii. Bax, E. \& Glebbeek, 2002. Labour turnover and its effects on performance: An empirical test using firm data. [Online] Available at: http://www.rug.nl/research/portal/publications/labourturnover-and-its-effects-on-performance\%28688fof 45 -873f-4a89-a1d7- 7f65aof8adf7\%29.html

iv. Baylor, A. \& Ritchie, D., 2012. What factors facilitate teacher skill, teacher morale, and perceived student learning in technology-using classrooms?. Computers \& Education, 39(4), 395-414. [Online] Available at: http://www.sciencedirect.com/science/article/pii/So360131502000751 [Accessed 21 December 2015].

v. Billet, S., 2014. Learning through work: workplace affordances and individual engagement.Journal of workplace learning, 13(5), 209-214. [Online] Available http://www98.griffith.edu.au/dspace/bitstream/handle/10072/3842/jwl_2.pdf?sequence=1 [Accessed 21 December 2015].

vi. $\quad$ Brown, n.d. Employee orientation: Keeping new employees on board. Duke Street, Alexandria: s.n.

vii. $\quad$ Brum, n.d. What impact does training have on employee commitment and employee turnover?. Rhode Island: Schmidt Labor Research Center, University of Rhode Island.

viii. Courtney, N., 2009. Improving students' learning outcomes. Portland, OR: Copenhagen Business School Press.

ix. Courtney, N., Holtham, C. \& Nygaard, C., 2009. Improving students' learning outcomes. Portland, OR: Copenhagen Business School Press.

x. D.B. Ellis \& College Survival, Inc, 2003. Bandura's social cognitive theory: An introduction. San Luis Obispo, CA: Davidson Films.

xi. $\quad$ Danks, 2011. The ADDIE Model: Designing, evaluating instructional coach effectiveness. s.l.:s.n.

xii. $\quad$ Ellis, D. B., \& College Survival, Inc., 2003. Learning styles inventory. Rapid City, SD: Houghton Mifflin Co.

xiii. Hamberg, H., 2002. Reasons given for employee turnover in a full priced department Store. Stout: University of Wisconsin, Stout.

xiv. Huckman, S. \& Ton, 2008. Managing the impact of employee turnover on performance: The Role of Process Conformance. Boston: s.n.

xv. Kingsbury, K., 2011. Learning. Grand Rapids, Mich: Zondervan.

xvi. Kolb, A., 2013. The Kolb learning style inventory-version 3.12005 technical specifications. Boston, MA: Hay Resource Direct, 200.

xvii. Lewis, L. \& Williams, C., 2015. Experiential learning: Past and present. New Directions for Adult and Continuing Education, 1994(62). [Online] Available at: $\quad$ http://www.sunyjcc.edu/files/Experiential\%20Learning\%20\%20Past\%20and\%20Present.pdf [Accessed 21 December 2015]. 
xix. Ministry of Education, n.d. Ministry of Education. [Online] Available at: http://he.moe.gov.sa/en/default.aspx

xx. MOE Mission, n.d. MOE Study Abroad Mission. [Online] Available at: http://he.moe.gov.sa/en/studyaboard/King-Abdulla-hstages/Pages/mission-a.aspx

xxi. MOE Vision, n.d. MOE Study Abroad Vision. [Online] Available at: http://he.moe.gov.sa/en/studyaboard/King-Abdulla-hstages/Pages/Vision-a.aspx

xxii. Mustapha, R. \& Abdullah, A., 2015. Malaysia Transitions toward a Knowledge-Based Economy.Journal of Technology Studies, 30(3). [Online] Available at: http://www.epu.gov.my/c/document library/get file?uuid=e8b18de7-of6c-4a178fab-e4a8f504ddd8\&groupId=283545

[Accessed 21 December 2015].

xxiii. New Zealand Qualification Authority, n.d. What is Self-Assesment. [Online] Available at: $\quad$ http://www.nzqa.govt.nz/providers-partners/self-assessment/what-is-selfassessment/[Accessed 21 December 2015].

xxiv. Noonan, B. \& Duncun, R., 2005. Peer and Self-Assessment in High Schools. Practical assessment, research and evaluation, 10(17), 1531-7714. [Online] Available at: http://pareonline.net/pdf/v10n17.pdf [Accessed 21 December 2015].

xxv. Shumway, 2013. AMEE Guide No. 25: The assessment of learning outcomes for the competent and reflective physician. Medical Teacher, 25(6), pp. 569-584.

xxvi. Teachinglearningresources.pbworks.com, 2015. Teaching and Learning Resources /Andragogy-Adult Learning Theory. [Online] Available at: http://teachinglearningresources.pbworks.com/w/page/30310516/Andragogy-Adult\%20Learning\%20Theory [Accessed 15 December 2015].

xxvii. $\quad$ Veres, J., Sims, R. \& Locklear, T., 2011. Improving the reliability of Kolb's revised learning style inventory. Educational and Psychological Measurement, 51(1), 143-150. [Online] Available at: http://www.bu.edu/ssw/files/2010/10/Kolbs-Learning-Style- Inventory-Issues-of-Reliabilityand-Validity1.pdf [Accessed 21 December 2015]. 


\section{Appendix}

\section{Q.1 what is the employee's attitude towards their jobs?}

Al-Sahlee

The new employees are dissatisfied because they do not fully understand their job descriptions Talat

Most of the employees lack motivation because they lack the skills required to perform their duties Mohammed

The employees are unable to meet the objectives because it is unclear what these objectives are

\section{Rahseed}

The employees are dissatisfied as they are unaware of how to accomplish the tasks given to them.

\section{Al-Salamn}

The employees claim that they only perform their duties the best way they know how as there is little supervision

\section{Q.2 what are some of the problems that the new employees encounter?}

\section{Al-Sahlee}

They often have a hard time catching up with the way the organization operates.

Talat

The new employees feel alienated because they is no supervision to bring them up to speed

Mohammed

They are often troubled by small tasks because they lack adequate training

Rahseed

They are exposed in an environment that is unconducive and this greatly lacks their performance

Al-Salamn

The employees lack a sense of belonging and are constantly looking to fit in but this often takes too long.

\section{Q.3 what do $u$ think is the reason behind the high turnover rate at the school?}

\section{Al-Sahlee}

The lack of orientation training leaves the employees clueless and this makes it hard for them to fit in

Talat

The employees lack training which makes it difficult for them to perform various tasks and this makes the working environment difficult for them

Mohammed

There is constant hazing from the old employees which discourages and alienates the new employees

\section{Rahseed}

Hazing by the old employees destroys the new employee's morale forcing them to seek employment elsewhere

\section{Al-Salamn}

There is lack of orientation training and the employee are unaware of the organization's culture and objectives and they opt to move to a place where they feel like they belong 